\title{
Prevention of salt induced hypertension in rats by oral administration of Lactobacillus acidophilus Yoghurt
}

\author{
Osuntoki, A.A ${ }^{1 *}$, Omonigbehin, E. A. ${ }^{2}$, Gbenebitse, S.O. ${ }^{3}$ and Mojiminiyi, U. E. ${ }^{3}$ \\ ${ }^{1}$ Department of Biochemistry, College of Medicine, University of Lagos. \\ PMB 12003, Lagos, Nigeria. \\ ${ }^{2}$ Genetics Division, Nigerian Institute of Medicine, University of Lagos. \\ *Author for correspondences:E-mail:niyiosuntoki@yahoo.co.uk
}

\begin{abstract}
A high salt diet can elevate blood pressure in humans and other susceptible animal species. A high proportion of our indigenous foods are fermented products and Lactobacillus species have been reported to be the predominant flora in many of our indigenous fermentation processes. In this study, the effect of concurrent oral administration of a yoghurt (produced by fermenting skimmed milk with a strain of L. acidophilus isolated from an indigenous fermented food) on salt loaded male
\end{abstract}

ABSTRACT

Sprague-Dawley rats was investigated. The acidophilus yoghurt was found to prevent the development of hypertension in the salt loaded rats $(\mathrm{p}<0.05)$ without significant changes in heart rate, plasma $\mathrm{Na}^{+}, \mathrm{Cl}^{-}, \mathrm{HCO}_{3}^{-}$ levels. This shows a potential application of Lactobacillus derived probiotics in the prevention of cardiovascular disease risk factor.

Key words: Hypertension, salt, Lactobacillus acidophilus, probiotic, yoghurt.

\section{INTRODUCTION}

$\mathbf{H}$

ypertension is a major cause of cardiovascular disease morbidity and mortality. An association between diet and hypertension has been established; high salt intake is an identified risk factor for the development of hypertension in susceptible individuals (INTERSALT, 1988; Tobian, 1997). Salt restriction and low salt diets have been shown to lower blood pressure in both normotensive and hypertensive subjects (Morgan and Myers, 1981; Sacks et al., 2001, Ebuehi et al 2003). However, salt restriction may not be generally acceptable because salt in diet plays three important roles; it serves as a preservative, adds palatability to meals and provides the bodily requirement for sodium.

The emerging trends in cardiovascular diseases in the developing world may reach the

level in the developed world where it is the main cause of morbidity if not curtailed.

The developing world can ill afford this, because many of these countries are being ravaged by the Human Immunodeficiency Virus (HIV), other infectious diseases and malnutrition. Further strains on already fragile health delivery systems may lead to a total collapse. It has thus become a necessity to explore low cost ways of preventing increases in chronic non-communicable diseases.

There has been a considerable interest in the probiotic use of Lactobacillus species and there are numerous reports on the beneficial health effects of these organisms (Reid, 1999; Anuradha and Rajeshwari, 2005). As far back as 1907, the good health and longevity of Bulgarians was attributed to the consumption of yoghurt, a fermented product containing various species of Lactobacillus (Metchnikoff, 1907). Reports of 
experiments on spontaneously hypertensive rats (SHR) have shown that milk fermented with $L$. heveticus and casein hydrolysates produced by this organism have orally active anti-hypertensive activity (Yamamoto et al., 1994; 1999). Cell wall polysaccharide-glycoprotein complexes of $L$. casei have also been reported to have antihypertensive activity in SHR and renal hypertensive rats (Sawada et al., 1990; Furushiro et al., 1993). However, to the best of our knowledge, no report exists on the effects of consumption of Lactobacillus fermented products in the prevention of salt induced hypertension.

In this study, using an animal model for salt induced hypertension, we have investigated the effect of consumption of acidophilus yoghurt on the development of hypertension in salt loaded Sprague-Dawley rats.

\section{MATERIALS AND METHODS} Bacterial strain, media and growth conditions

The Lactobacillus acidophilus used to produce the yoghurt was a non-commercial strain isolated from wara; a traditional, Nigerian soft unripened cheese produced by the addition of leaf extracts of Calotropsis procera to whole cow milk. The Lactobacillus was maintained in MRS broth (de Man et al. 1960) containing $50 \%$ glycerol (V/V) and stored at $-20^{\circ} \mathrm{C}$. Before use the organism was cultivated on MRS agar (Oxoid, UK) for $1 \mathrm{~d}$ at $37{ }^{\circ} \mathrm{C}$ under anaerobic conditions using a disposable gas generating kit (Anaerobier system; Oxoid).

\section{Acidophilus yoghurt preparation}

The yoghurt preparation method of Reddy et al .(1983) was adapted; under aseptic conditions, $10 \mathrm{~g}$ skimmed milk was dissolved in $500 \mathrm{ml}$ sterile $2 \%$ milk. The mixture was heated for $30 \mathrm{~min}$ at $80{ }^{\circ} \mathrm{C}$, cooled to $42{ }^{\circ} \mathrm{C}$ and inoculated with $15 \mathrm{ml}$ actively growing $L$. acidophilus culture in $2 \%$ milk, then incubated for $2 \mathrm{~d}$ at $37^{\circ} \mathrm{C}$. The product was stored frozen in sterile containers.

\section{Animal bioassay}

Twenty four inbred male Sprague-Dawley (S-D) rats 12-14 wk old weighing 120 - 150g were obtained from the Laboratory Animal Centre, College of Medicine, University of Lagos. The rats were housed two per cage in a metabolic room with a temperature of $28 \pm 2{ }^{\circ} \mathrm{C}$, subjected to a regimen of 12 day/night cycles and given unlimited access to food and water before and during the study. The rats were allowed to acclimatize to our laboratory conditions for 14 days and randomized into four groups of six rats each. Group 1 rats (control) were fed with normal rat chow. Group 2 rats were given a salt loaded diet (rat chow containing 8 $\% \mathrm{NaCl}$ ). Groups 3 and 4 were fed the same diet as Group 2 but in addition $1 \mathrm{ml}$ skimmed milk $(0.18 \mathrm{~g} / \mathrm{ml})$ or acidophilus yoghurt respectively was administered orally, by gavage daily. The quantity of the dairy products administered was calculated based on the estimated daily consumption of a $70 \mathrm{~kg}$ human. At the end of a $5 \mathrm{wk}$ feeding period, blood pressure, heart rate and some plasma electrolytes levels were determined.

\section{Measurement of blood pressure and heart rate}

The rats were anaesthetized with an intraperitoneal injection of $25 \%$ urethane $(\mathrm{BDH}$ Laboratories, UK) $1 \%$ a-chloralose (BDH) in normal saline at a dose of $5 \mathrm{ml}$ per $\mathrm{kg}$ body weight. The right femoral artery was cannulated and connected to a pressure transducer (Statham P23 LD) coupled to a model 7D polygraph (Grass instruments Ltd., U.S.A) for pressure pulse recording. The transducer was calibrated using an anaeroid sphygmomanometer (Grass model 7P8F). Mean arterial pressure (MAP) was calculated as one third pulse pressure plus diastolic pressure. Heart rate was determined by 
counting the number of arterial pulses in $15 \mathrm{~s}$ and expressed in beats per minute (bpm).

\section{Plasma electrolytes determination}

Blood was collected from the cannulated artery into heparinized bottles. The plasma was collected after centrifugation and the levels of $\mathrm{Na}^{+}, \mathrm{Cl}^{-}$and $\mathrm{HCO}_{3}^{-}$were analyzed using a Beckman CX5 autoanalyzer (Beckman Instruments, U.S.A.).

\section{Statistical Analysis}

The mean values obtained for each parameter determined were assessed for statistical significance by one way analysis of variance (ANOVA). Differences in mean values between groups were analyzed for significance using student's t-test. Two tail probability values were calculated and a probability level of $\mathrm{p}<0.05$ was considered significant.

\section{RESULTS AND DISCUSSION}

Salt loading induced a significant increase in the blood pressure of the S-D rats. The systolic blood pressure (SBP), diastolic blood pressure (DBP) and mean arterial pressure (MAP) were significantly higher in the salt loaded rats compared to the control rats and the acidophilus yoghurt fed rats. Consumption of the acidophilus yoghurt (produced by fermenting skimmed milk with L. acidophilus) prevented the blood pressure elevation associated with salt loading while skimmed milk had no effect on the development of hypertension. The salt loaded rats had a significantly higher heart rate (HR) while there was no significant difference between the HR of the control and the other two groups. The pulse pressure (PP) was not significantly different between groups. When compared to the salt loaded group, there was no significant difference in any of these parameters between the salt loaded group and the salt loaded group administered with skim milk (Table 1).

No significant difference in the levels of the electrolytes measured, $\mathrm{Na}^{+}, \mathrm{Cl}^{-}$and $\mathrm{HCO}_{3}{ }^{-}$, were seen (Table 2). A high salt diet has been reported to cause elevation in arterial blood pressure in susceptible animal species which includes humans (Tobian,1997; Sofola et al 2002). The results of our study are in agreement with previous reports on salt induced blood pressure elevation in S-D rats (Miyajima \& Bunag, 1985; Sofola et al., 2002). However, we observed that rats concurrently consuming acidophilus yoghurt along with a high salt diet did not show the rise in blood pressure associated with salt loading.

Fermented products constitute a significant portion of African diets and Lactobacillus species are involved in many of the indigenous fermentation processes (Odunfa 1985). The discovery of in vivo hypertension prevention activity by a product fermented with a Lactobacillus strain isolated from an indigenous fermented food and previous reports of antihypertensive activity exhibited by lactobacilli (Yamamoto et al., 1994; 1999 ) raises the possibility that other lactobacilli from various fermented foods have similar orally active antihypertensive action and that some fermented foods may have natural antagonistic effects on hypertension risk factors or have hypotensive effects.

The incidence of hypertension has been reported to be lower in rural areas in Nigeria (Akinkugbe, 1997; Kaufman et al.,1999). Many urban dwellers have lifestyles, which increase the level of stress and westernized dietary habits which increase salt intake and exclude or reduce the consumption of local diets, thus limiting or excluding the potential beneficial blood pressure effects.

From our results, we postulate that the exclusion or a significant reduction of indigenous fermented foods from the diets of urban dwellers is a factor in the observed higher incidence of hypertension in the urban areas and may be contributory to the increasing trends observed in 
recent reports on developing countries (WHO 2002).

A comprehensive screening of the Lactobacillus flora of indigenous fermented products for anti-hypertensive activity is thus imperative to determine the veracity of this postulation.

\section{CONCLUSION}

In the developed world a key priority of the food industry is the development of foods that promote health and well being. The results of this study show hypertension prevention activity by a strain of $L$. acidophilus isolated from an indigenous fermented food. This indicates that our indigenous microbial species are potentially exploitable for the development of health promoting food systems.

\section{REFERENCES}

Akinkugbe,O.O.(1997).Non communicable diseases in Nigeria. Final report of a national survey. Lagos : Federal Ministry of Health and Social Services. p. 12-41.

Anuradha, S.and Rajeshwari, K. (2005). Probiotics in health and disease. J. Ind. Acad. Clin. Med. 6: 67-72.

de Man J. C., Rogosa M. and Sharpe M.E. (1960). A medium for cultivation of lactobacilli. J. Appl. Bacteriol 23: 130-135.

Ebuehi, O.A.T, Elekolusi O.A, Adegunloye B.J and Mojiminiyi F.B.O (2003) Effect of dietary salt/loading on blood presure and erythrocyte $\mathrm{Na}+\mathrm{K}^{+}-$ATP ase in rats. Afri. J. Medicine and Pharmaceut Sci. 7, 27-35.

Furushiro M., Hashimoto S., Hamura M.and Yokokura T.(1993). Mechanism for the antihypertensive effect of a polysaccharide - glycopeptide complex from Lactobacillus casei in spontaneously hypertensive rats (SHR). Biosci. Biotechnol. Biochem. 57, 978-981.

INTERSALT Cooperative Research Group (1988). INTERSALT: an international study of electrolyte excretion and blood pressure. Results for 24 hour urinary sodium and potassium excretion. BMJ 297, 319-328.

Kaufman J.S., Owoaje E. E. Rotimi C.N.and Cooper R. S.(1999). Blood pressure change in Africa: case study from Nigeria. Hum. Biol.71, 641-657.

Metchnikoff E.(1907). The prolongation of life. Butterworth- Heinemann: London

Miyajima E. and Bunag, R. D.(1985). Dietary salt loading produces baroflex impairment and mild hypertension in rats. Am. J. Physiol. 249, $\mathrm{H} 278-\mathrm{H} 284$.

Morgan, T. W. and Myers, J. B.(1981). Hypertension treated by by sodium restriction. Med. J. Aust. 2,396-397.

Odunfa S. A.(1985). African fermented foods. In B. J. Wood (ed) : Microbiology of fermented foods. Elsevier, London, New York. Vol 2, pp. 155-191.

Reddy G.V., Friend B. A., Shahani K.M. and Farmer R. E.(1983) Antitumor activity of yogurt components. J. Food Prot. 46, 8-11.

Reddy, K.S. (2002). Cardiovascular diseases in the developing countries: dimensions, determinants, dynamics and directions for public health action. Public Health Nutrition, 5:231-237. 
Reid, G. (1999). The scientific basis for probiotic strains of Lactobacillus. Appl. Environ. Microbiol. 65,3763-3766.

Sacks F.M., Svetkey L.P., Vollmer W.M., Appel L.J., Bray G.A., Harsha D., Obarzanek E., Conlin P.R., Miller E.R. III, Simons-Morton D.G., Karanja N. and Lin P-H.(2001). Effects on blood pressure of reduced dietary sodium and the dietary approaches to stop hypertension (DASH) diet. N. Engl. J. Med. 344, 3-10.

Sawada, H., Furushiro, M., Hirai, K., Motoike, M., Watanabe, T. and Yokokura, T. (1990). Purification and characterization of an antihypertensive compound from Lactobacillus casei. Agric. Biol. Chem. 54, 3211-3219.

Sofola, O. A., Knill,A., Hainsworth,R. and Drinkhill, M.(2002). Change in endothelial function in mesenteric arteries of Sprague Dawley rats fed a high salt diet. J. Physiol. 543, 255-260.
Tobian, L. (1997). Dietary sodium chloride and potassium have effects on the pathophysiology of hypertension in humans and animals. Am. J. Clin. Nutr. 65, 606S-611S.

WHO: Innovative care for chronic conditions: building blocks for action: global report.pp.1129. WHO document no. WHO/NMC/CCH/ 02.012002.

Yamamoto, N., Akino, A. and Takano, T.(1994). Antihypertensive effect of the peptides derived from casein by an extracellular proteinase from Lactobacillus helveticus CP 790. J. Dairy Sci. 77, 917-922.

Yamamoto N., Maeno M. and Takano T.(1999) Purification and characterization of an anti hypertensive peptide from a yogurt - like product fermented by Lactobacillus helveticus CPN4. J. Dairy Sci. 82, 1388-1393.

Table1: Systolic blood pressure (SBP), diastolic blood pressure (DBP), mean arterial pressure (MAP), pulse pressure (PP) and heart rate (HR) of the rat groups.

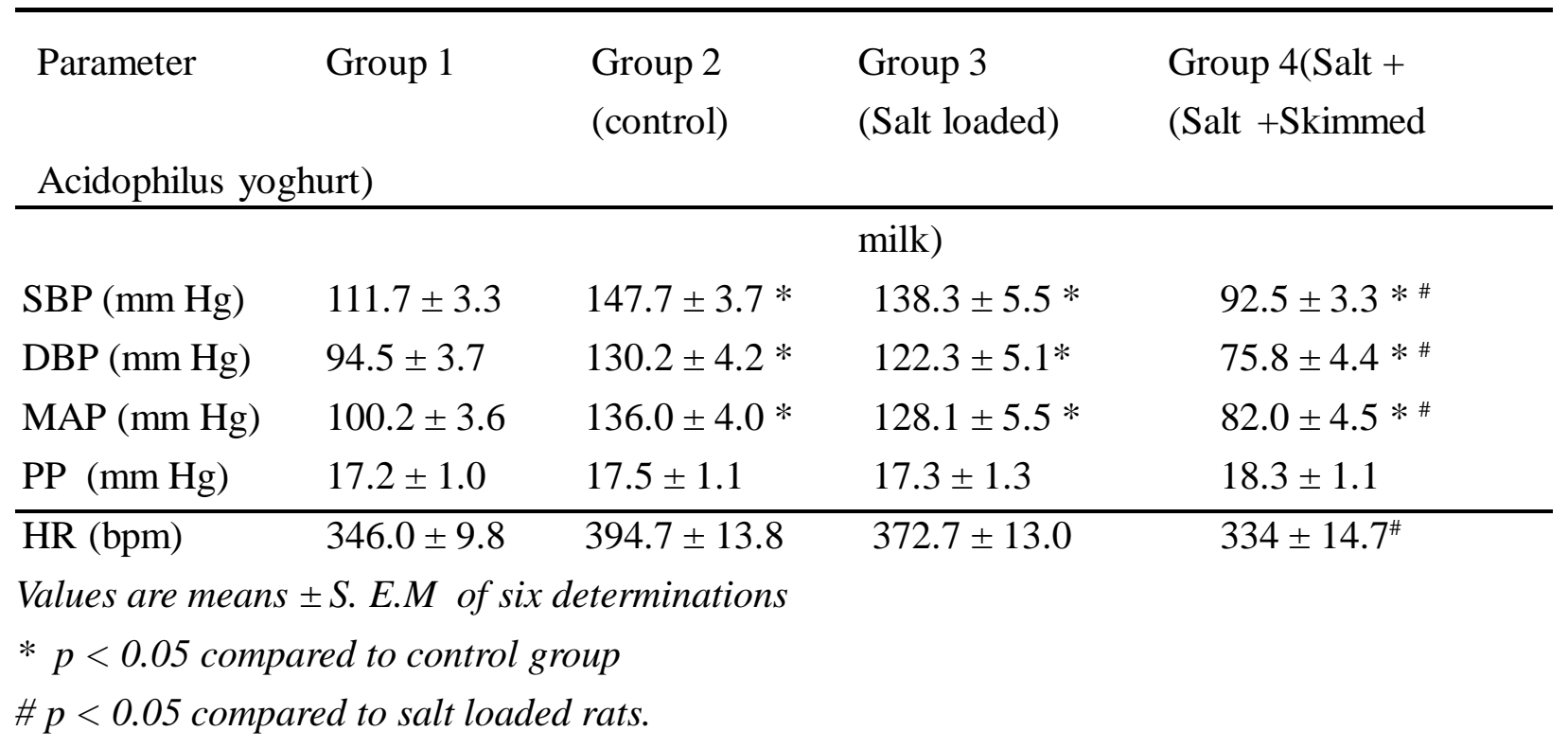


Table 2: Some plasma electrolytes levels in the rat groups.

\begin{tabular}{lllll}
\hline Electrolytes & $\begin{array}{l}\text { Group 1 } \\
\text { control })\end{array}$ & $\begin{array}{l}\text { Group 2 } \\
\text { (Salt loaded) }\end{array}$ & $\begin{array}{l}\text { Group 3(Salt } \\
+ \text { Skimmed milk) }\end{array}$ & $\begin{array}{l}\text { Group 4(Salt } \\
+ \text { Acidophilus } \\
\text { yoghurt })\end{array}$ \\
\hline $\mathrm{Na}^{+}(\mathrm{mmo} / \mathrm{L})$ & $125.8 \pm 3.4$ & $137.6 \pm 2.2$ & $128.5 \pm 5.0$ & $127.5 \pm 4.3$ \\
$\mathrm{Cl}^{-}(\mathrm{mmol} / \mathrm{L})$ & $96.5 \pm 2.2$ & $112.1 \pm 5.9$ & $98.2 \pm 3.8$ & $99.3 \pm 3.9$ \\
$\mathrm{HCO}_{3}^{-}(\mathrm{mmol} / \mathrm{L})$ & $18.0 \pm 0.8$ & $18.4 \pm 0.6$ & $19.0 \pm 0.6$ & $17.8 \pm 0.7$ \\
\hline
\end{tabular}

Values are means \pm S.E.M of six determinations 